\title{
Changing prevalence of asthma in Turin school children between 1994 and 1999
}

\author{
E. Migliore1, P. Piccioni1, G. Garrone2, G. Ciccone3, \\ A. Borraccino4, M. Bugiani ${ }^{1}$
}

ABSTRACT: Changing prevalence of asthma in Turin school children between 1994 and 1999. E. Migliore, P. Piccioni, G. Garrone, G. Ciccone, A. Borraccino, M. Bugiani.

Beckground: Asthma is a widespread chronic disorder in children and its prevalence has been on the increase in Europe. Only few studies have described the prevalence variation in respiratory symptoms in Italian regions.

The aim of this study, conducted in Turin during the $1998 / 1999$ school year, is to investigate the distribution of respiratory symptoms in a sample of Turin school children and to compare the obtained results with the findings of the SIDRIA study performed in 1994-95.

Methods: the sample in study is composed of all the children attending to three elementary schools in Turin. All of the selected schools had already participated in the 94-95 ISAAC-SIDRIA study. A total of $\mathbf{4 4 8}$ pupils aged 610 years received a standardised questionnaire to be filled by parents.

Results: response rate is higher than $97 \%$ in all the studies. In 1999 we found that the prevalence of wheezing in the past 12 months was $7.3 \%$. The $13.3 \%$ of children had asthma at least once in life and the $5.3 \%$ reported an attack in the last year.

The comparison of our study results with the ISAACSIDRIA (1994-95) shows that the prevalence of asthma and asthma-like symptoms is rather stable among children, while the prevalence of bronchitis reveals a reduction of about $5.5 \%$, but not statistically significant $(p=0.094 ; 95 \% C I:-11.9 ; 0.9)$. A considerable reduction in exposure to parents' passive smoke is shown: $\Delta \mathrm{P} \%=-4.7$ (95\% CI: -9.4;-0.1) for maternal smoking in pregnancy, $\Delta \mathbf{P} \%=-8.2$ and $\mathbf{- 1 5 . 2}$, respectively for maternal and paternal smoking in the first two years of life.

Conclusions: The results indicate a stable prevalence rate in asthma symptoms in children. A possible explanation of slight variation in asthma prevalence may be due to a reduced exposure to outdoor and indoor risk factors as reported in the questionnaires.

Monaldi Arch Chest Dis 2005; 63: 2, 74-78.

Keywords: Asthma, childhood, prevalence.

1 CPA-ASL4, Turin

2 Paediatrics' Service ASL4, Turin.

3 Cancer Epidemiology Unit - CPO Piedmont

4 Public Health Department - University of Turin, Italy.

Correspondence: Dr. Massimiliano Bugiani; CPA-ASL4, Lungo Dora Savona 26, 10131 Torino, Italy; e-mail: maxbugiani@libero.it

\section{Introduction}

Asthma is a widespread chronic disorder in children and its social impact is relevant. Over the last decade asthma prevalence has been on the increase in Europe [1,2], the United States [3], Australia [4] and New Zealand [5], with a parallel increase in emergency admissions and hospitalisation rate [6].

More recent studies have however suggested that its distribution is reaching a plateau. The reasons are to be sought in increased attention to its diagnosis among physicians and in more effective treatment strategies able to stem its progress $[2,3]$.

The ISAAC study results [1994-95] confirmed a very large geographical variation in asthma prevalence in Western countries [7, 8]; the Italian areas involved in the study showed a prevalence rate of approximately $9 \%$ in children aged 6-7 and 13-14, with limited differences between them.
In the last year, some studies report no changes in the prevalence of wheeze, asthma and atopic sensitisation among children and adolescents $[9,10]$ and two studies indicate a significant decrease of these diseases [11, 12].

In recent years only a few studies have described the prevalence variation in respiratory symptoms in Italian regions; the ISAYA (Italian Study on Asthma in Young Adults), performed between 1998 and 2000 on young adults in Italy, showed a negligible or very slight increase in symptoms distribution [13]. Another study has revealed a considerable increase in allergic rhinitis in the last 12 months and in eczema in life, while there is no evidence of any significant variation in asthma and asthma-like symptoms [14].

The aims of our study, conducted in Turin during the 1998-1999 school year, are to investigate the distribution of respiratory symptoms, skin and nasal allergies in relation to their principal envi- 
ronmental risk factors in a sample of Turin school children and to compare the results obtained with the findings of the SIDRIA study (Italian Study of Respiratory Diseases in Childhood and the Environment) performed in 1994-95 [15, 16, 17, 18] on school children in a Turin suburb, with the objective of describing a temporal trend in the conditions analyzed.

\section{Materials and methods}

In the 1994-95, 28 schools were sampled in four catchment's areas of National Health Service to participate to the SIDRIA study, an extension of the international ISAAC study [19]. In the 1999 we selected one of the four areas (area 4) for an intermediate survey repetition between the old and the new SIDRIA study.

The survey took place between March and May 1999, in three schools of the catchment's area 4 using the 1994 SIDRIA protocol sampling procedure [19]; a total of 448 pupils aged 6-10 years received a self-administered questionnaire to be filled in by parents. The sampled children have been compared with the 445 pupils, participating to the 1994 survey and attending to the same three schools. In order to make the results comparable, the questionnaire and the administration methods were the same used in the SIDRIA study [19].

The standardised questionnaires comprise 84 items organized into three different sections.

- Section 1 contains questions on the subject's health and socio-demographic characteristics. More specifically, the questions investigate the medical diagnosis of asthma and asthma-like symptoms (presence of wheeze at rest or with exercise, shortness of breath, dry cough, phlegm and chest tightness); rhinitis (frequent sneezing, runny or blocked nose not of cold or flu, itchy or watery eyes); eczema and skin allergies (itchy rash for at least 6 months).

- Section 2 investigates medical treatment with questions on drug consumption, hospital care and treatment administered.

- Section 3 questions on risk factors, with information about the child's first two years of life (gestational age, birth weight, breast feeding, exposure to smoke and allergens); diet, sports activity and lifestyle; socio-economic information regarding the parents (nationality, study title and profession), together with their smoking habits and parental asthma and allergies.

Descriptive analysis estimates the prevalence of the principal variables collected, focusing on the frequency of the principal respiratory symptoms (presence of wheezing, asthma, allergic symptoms and eczema). For the temporal comparison between the two surveys, the effect measure was the absolute difference between the prevalence recorded in 1994-95 and in 1999, delta $(\Delta)$ together with $95 \%$ CI. Prevalence and $\Delta$ were calculated using generalised linear models (GLM) adjusted for sex and age, where each symptom was considered as response variable and survey period as predictive variable.

All the statistical analyses have been performed using the statistical package Stata 8.0 version [20].

\section{Results}

A total of 435 and 445 children had completed the questionnaire in 1994-95 and in 1999 respectively (response rate was higher than $97 \%$ in both studies). The distribution of gender and age was similar in the two surveys. For non responders, concerning the last study, the main cause of failure to return the questionnaire was due to the language difficulties of foreign families and only in a very small number were explicit refusals to participate (two cases).

Table 1 reports the distribution and the changes in the main characteristics of exposures of study population between the two studies. The proportion of mothers with high study title (secondary school or degree) and currently employed increased between 1994-95 and 1999 and the proportion of fathers currently employed increased significantly $(\Delta \mathrm{P} \%=7.2 ; \mathrm{CI} 95 \%=1.5 ; 12.9)$. The reduction in exposure to parents' passive smoke was particularly evident: both smoking during pregnancy $(\Delta \mathrm{P} \%=-4.7 ; 95 \% \mathrm{IC}=-9.4 ;-0.1)$ and parents' smoking in the first two years of the child's life $(\Delta \mathrm{P} \%=-8.2$ for the mother and $\Delta \mathrm{P} \%=-15.2$ for the father) showed a statistically significant decrease. Similarly, we observed a decrease of intense road traffic exposure prevalence $(-5.4 \%)$ between 1994 and 1999, but not statistically significant $(\mathrm{p}=0.106)$

In the section on behaviour we found a significant increase only in the number of subjects practicing outdoor sporting activities $(\Delta \mathrm{P} \%=7.4$; $\mathrm{p}=0.02)$, while dietary habits remained roughly the same.

Tables 2 summarises the changes in overall prevalence of respiratory symptoms, asthma and allergies adjusted for sex and age. Both in 1994-95 and in 1999 surveys, all the respiratory symptoms analysed show a higher prevalence in male subjects than in females (data not shown), but the differences were not statistically significant.

The proportion of children with asthma is $13.3 \%$ and $39.8 \%$ (5.3\% out of the whole group) have had an asthma attack in the last 12 months. With regard to asthma drug assumption, all the children with at least an asthma attack in the last 12 months took treatment when needed and $42.1 \%$ of them regularly ( $2.1 \%$ of the total). Bronchitis symptoms are present in $35.7 \%$ of children during their lifetime and in $8.2 \%$ in the last 12 months. Thirty-four children have had at least one episode of hay fever in their lives and $9.0 \%$ of children suffered from nasal allergies with itching and watery eyes, typical of allergic rhinitis. Finally, $18.2 \%$ of the children had had eczema once in their lives.

The comparison between 1994 and 1999 reveals a similar representation of the principal symptoms 


\begin{tabular}{|c|c|c|c|c|c|}
\hline & $\begin{array}{c}1994 / 95 \\
\%\end{array}$ & $\begin{array}{c}1999 \\
\%\end{array}$ & $\Delta \mathbf{P} \% *$ & $95 \% \mathrm{CI}$ & $\mathbf{p}$ \\
\hline Subjects studied (n) & 445 & 435 & & & \\
\hline Response rate $(\%)$ & 97.6 & 97.1 & & & \\
\hline Male gender & 49.2 & 49.7 & & & \\
\hline Age (mean) & 7.6 & 7.8 & & & \\
\hline \multicolumn{6}{|l|}{ Parent's characteristics } \\
\hline Mother' education (secondary school or degree) & 30.9 & 34.0 & 3.1 & $-3.2 ; 9.4$ & 0.335 \\
\hline Mother currently employed & 49.7 & 54.1 & 4.4 & $-4.8 ; 13.7$ & 0.353 \\
\hline Mother current smoker & 33.6 & 29.4 & -4.3 & $-10.4 ; 1.9$ & 0.179 \\
\hline Maternal smoking during pregnancy & 16.4 & 11.6 & -4.7 & $-9.4 ;-0.1$ & 0.045 \\
\hline Maternal smoking in the first two yrs of life & 29.3 & 21.1 & -8.2 & $-13.9 ;-2.4$ & 0.005 \\
\hline Father' education (secondary school or degree) & 28.4 & 31.4 & 3.0 & $-3.1 ; 9.2$ & 0.335 \\
\hline Father currently employed & 87.8 & 95.0 & 7.2 & $1.5 ; 12.9$ & 0.013 \\
\hline Father current smoker & 55.4 & 49.6 & -5.8 & $-12.5 ; 0.9$ & 0.090 \\
\hline Paternal smoking in the first two yrs of life & 55.9 & 40.7 & -15.2 & $-21.8 ;-8.6$ & 0.001 \\
\hline Parental history of asthma & 6.5 & 9.7 & 3.2 & $-0.5 ; 6.8$ & 0.087 \\
\hline \multicolumn{6}{|l|}{ Life habits and traffic exposure } \\
\hline Outdoor sports & 10.8 & 18.2 & 7.4 & $1.2 ; 13.5$ & 0.020 \\
\hline Assumption of Vit. C ( 3 or more times for week) & 58.1 & 56.1 & -1.9 & $-11.2 ; 7.3$ & 0.677 \\
\hline Added Salt & 3.8 & 4.6 & 0.8 & $-1.9 ; 3.5$ & 0.561 \\
\hline Breast feeding & 69.1 & 65.7 & -3.3 & $-11.9 ; 5.3$ & 0.448 \\
\hline Pets in the first 2 yrs of life & 24.5 & 22.3 & -2.2 & $-10.1 ; 5.7$ & 0.585 \\
\hline High traffic density in zone of residence & 44.6 & 39.2 & -5.4 & $-11.9 ; 1.1$ & 0.106 \\
\hline
\end{tabular}

$\Delta \mathrm{P} \% *=$ difference in percent between 1994 and 1999.

Table 2. - Changes ( $\Delta$ and $95 \% \mathrm{Cl}$ ) in prevalence of respiratory symptoms in the survey SIDRIA (1994-1995) and in the 1999 survey

\begin{tabular}{|c|c|c|c|c|c|}
\hline & $\begin{array}{c}1994 / 95 \\
\%\end{array}$ & $\begin{array}{c}1999 \\
\%\end{array}$ & $\Delta \mathbf{P} \% *$ & $95 \% \mathrm{CI}$ & $\mathbf{p}$ \\
\hline \multicolumn{6}{|l|}{ Asthma like symptoms } \\
\hline Wheezing (lifetime) & 24.1 & 21.9 & -1.8 & $-7.3 ; 3.7$ & 0.522 \\
\hline Wheezing (past 12 months) & 6.3 & 7.3 & 0.9 & $-2.4 ; 4.3$ & 0.578 \\
\hline Severe wheezing (past 12 months) & 0.9 & 1.6 & 0.7 & $-0.7 ; 2.2$ & 0.363 \\
\hline Nocturnal dry cough & 19.5 & 20.7 & 1.2 & $-3.8 ; 6.2$ & 0.645 \\
\hline Dispnoea with wheezing (lifetime) & 21.5 & 20.9 & -0.6 & $-5.5 ; 4.4$ & 0.819 \\
\hline Dispnoea with wheezing past 12 month) & 7.3 & 8.2 & 0.9 & $-2.2 ; 4.0$ & 0.564 \\
\hline \multicolumn{6}{|l|}{ Asthma } \\
\hline$\overline{\text { Asthma (lifetime) }}$ & 10.7 & 13.3 & 2.5 & $-1.4 ; 6.5$ & 0.211 \\
\hline Asthma (past 12 months) & 4.4 & 5.3 & 0.9 & $-1.6 ; 3.5$ & 0.482 \\
\hline Drug consumption (if necessary) & 3.6 & 5.3 & 1.7 & $-1.2 ; 3.9$ & 0.364 \\
\hline Drug consumption (regularly) & 0.7 & 2.1 & 1.5 & $-1.4 ; 3.8$ & 0.377 \\
\hline Hospital admission or emergency room for asthma & 4.3 & 5.0 & 0.7 & $-2.0 ; 3.4$ & 0.599 \\
\hline \multicolumn{6}{|l|}{ Bronchitic symptoms } \\
\hline Cough for three or more months a year & 6.2 & 4.3 & -1.9 & $-4.6 ; 0.8$ & 0.171 \\
\hline Phlegm for three or more months a year & 3.4 & 3.5 & 0.1 & $-2.2 ; 2.4$ & 0.941 \\
\hline Bronchitis (lifetime) & 41.2 & 35.7 & -5.5 & $-11.9 ; 0.9$ & 0.094 \\
\hline Bronchitis (past 12 months) & 8.9 & 8.2 & -0.7 & $-4.5 ; 3.0$ & 0.697 \\
\hline \multicolumn{6}{|l|}{ Nasal and skin allergies } \\
\hline Rhinitis symptoms (past 12 months) & 16.9 & 16.8 & -0.1 & $-4.8 ; 4.6$ & 0.966 \\
\hline Oculorhinitis symptoms (past 12 months) & 7.1 & 9.0 & 1.9 & $-1.4 ; 5.2$ & 0.263 \\
\hline Hay fever & 9.1 & 9.8 & 0.7 & $-2.6 ; 3.9$ & 0.684 \\
\hline Eczema & 15.3 & 18.2 & 2.9 & $-2.0 ; 7.9$ & 0.243 \\
\hline
\end{tabular}

*Changes adjusted for sex and age.

investigated with a slight increase in the reporting of diagnosed asthma $(\Delta=2.5)$ and an asthma attack in the last 12 months $(\Delta=0.9)$ but the observed differences do not reach statistical significance. Similar- ly, drug consumption for asthma in the last 12 months (both regularly and if necessary) slightly increases $(\Delta=1.5$ and $\Delta=1.7)$, as well as hospital admissions for asthma $(\Delta=0.7)$. 
Bronchitis in the child's lifetime prevalence shows a reduction of $5.5 \%(\mathrm{p}=0.094 ; 95 \% \mathrm{IC}=-11.9$; $0.9)$, while bronchitis episodes during the last year decreased by $0.7 \%$ : nevertheless neither of these findings are statistically significant.

Oculorhinitis symptoms show a slightly increase between 1994 and $1999(\Delta=1.9)$ and a similar trend is reported for diagnosis of atopic eczema, with an increase of prevalence of about $3 \%$.

\section{Discussion}

Epidemiological studies on bronchial asthma are widely represented in literature but, as reported in the introduction, the geographical distribution is still uncertain; the pathology is very frequent in Australia and New Zealand (20-40\%), while it is under represented in the United States (6-8\%); in Europe the highest prevalence rates are reported in England (13\%) and in Germany (11\%) [21]. These observed differences may be partly due to the used survey instruments, which often employ self-reported un-standardized questionnaires, and to the studied population as the latter have a different age distribution in the various countries studied.

Although knowledge of asthma pathogenesis is widespread, its etiology remains, still nowadays, a subject of debate. Indeed in recent years research has mainly regarded examining the principal environmental factors for asthma with particular attention to indoor and air pollution exposure [22, 23].

Trend variation over time suggests that asthma prevalence has been falling over the last ten years and as far as the city of Turin is concerned, our study confirms the low prevalence of asthma and asthma-like symptoms.

Similarly to what has been reported for young adults in Italy [13], asthma and asthma-like symptom prevalence in childhood has shown only a slight variation in recent years: the data in this study indicate a maximum increase in the prevalence in asthma attacks of 3.5 percent with a possible reduction to 1.6 percent in five years (with an annual increase of $0.7 \%$ ).

Drug consumption and asthma treatment in children seems to be steady or slightly increasing.

The reported increase in asthma diagnosis together with the negligible change in hospital admissions for asthma would appear to indicate an increase in the diagnostic sensitivity of clinicians and an overall improvement in the health treatment of asthmatic subjects which is also due to a wider acceptance and adoption of the GINA guidelines [24].

We have not observed an increase in the number of subjects in treatment, but this fact does not exclude an improvement in health care: this hypothesis may be confirmed by the adoption of preventive measures and the consequent reduction in the number of hospital admissions [25, 26]. Furthermore, the improvement in the average cultural level is an influential variable in indirectly improving treatment outcomes.
Another hypothesis to explain the slight variation in asthma prevalence may be due to a reduced exposure to outdoor and indoor risk factors as reported in the questionnaires (in particular the significant reduction in exposure to passive smoke and traffic).

Moreover, in past years the increase in prevalence of asthma-like symptoms was partly explained with an increase in air pollution. Recently (1991-1998) in the city of Turin such pollution has been falling, with a decrease especially in some pollutants: SO2 from 32.8 to $17.85 \mu \mathrm{g} / \mathrm{m} 3, \mathrm{O} 3$ from 5.8 to $4.0 \mathrm{mg} / \mathrm{m} 3$, and $\mathrm{NO} 2$ from 84.0 to 74.9 $\mu \mathrm{g} / \mathrm{m} 3$ [27].

This study is not without limitations: i) all the personal information collected has been retrieved by means of self-compiled questionnaires (this limitation was already present in the previous study); ii) the sample size, and as a consequence the low study power $(\Delta=0.3)$, may be partly responsible for the lack of statistical significance of some of the results discussed. Nevertheless, an even more extensive study would have been able to identify only slight increases as statistically significant, as may be seen in the confidence value interval.

In conclusion, asthma and asthma-like symptoms prevalence reveals a stable plateau during the last 10 years, just after the dramatic increase that constituted asthma prevalence during the past 20 years since the 1960s. The results of this study may be confirmed and examined in greater depth by repeating the SIDRIA/ISAAC study with a higher study power and with greater geographical coverage. In the near future further explanation on different diagnostic and treatment behaviour and the distribution of the principal risk factors may be expected.

\section{References}

1. Burney PGJ, Chinn S, Rona RJ. Has the prevalence of asthma increased in children? Evidence from the national study of health and growth. BMJ 1990; 300: 1306-1310.

2. Anderson HR, Butland BK, Strachan DP. Trends in prevalence and severity of childhood asthma. BMJ 1994; 308: 1600-1604.

3. Weitzman M, Gortmaker SL, Sobol AM, et al. Recent trends in the prevalence and severity of childhood asthma. JAMA 1992; 268: 2673-2677.

4. Peat JK, van den Berg RH, Green WF, et al. Changing prevalence of asthma in Australian children. BMJ 1994; 308: 1591-1596.

5. Shaw RA, Crane J, O'Donnell TV, et al. Increasing asthma prevalence in a rural New Zealand adolescent population: 1975-89. Arch Dis Child 1990; 65: 1319-1323.

6. Sears MR. Epidemiological trends in bronchial asthma. In: Kaliner MA, Barnes PJ, Persson CGA, eds. Asthma, its pathology and treatment. New York: M. Dekker Publ. 1992: 1.

7. Strachan DP, Sibbald B, Weiland SK, et al. Worldwide variation in prevalence of symptoms of allergic rhinoconjunctivitis in children: the International Study of Asthma and Allergies in Childhood. Pediatr Allergy Immunol 1997; 8: 161-176.

8. ISAAC Steering Committee. Worldwide variations in the prevalence of asthma symptoms: the International Study of Asthma and Allergies in Childhood (ISAAC). Eur Resp J 1998; 12: 315-335. 
9. Braun-Fahrlander C, Gassner M, Grize L, et al. No further increase in asthma, hay fever and atopic sensitization in adolescents living in Switzerland. Eur Respir J 2004; 23: 407-413.

10. Lee SL, Wong W, Lau YL. Increasing prevalence of allergic rhinitis but not asthma among children in Hong Kong from 1995 to 2001 (Phase 3 International Study of Asthma and Allergies in Childhood). Pediatr Allergy Immunol 2004; 15: 72-78.

11. Anderson HR, Ruggles R, Strachan DP, et al. Trends in prevalence of symptoms of asthma, hay fever and eczema in 12-14 year old in the British Isles, 19952002: questionnaire survey. BMJ 2004; 328: 10521053.

12. Toelle BG, Belousova E, Salome CM, Peat JK, Marks GB. Prevalence of asthma and allergy in schoolchildren in Belmont, Australia: three cross sectional surveys over 20 years. BMJ 2004; 328: 386-387.

13. G Verlato, A Corsico, S Villani, et al. Is the prevalence of adult asthma and allergic rhinitis still increasing? Results of an Italian Study. J Allergy Clin Immunol 2003; 111: $1232-1238$.

14. Ronchetti R, Villa MP, Barreto M, et al. Is the increase in childhood asthma coming to an end? Findings from three surveys of schoolchildren in Rome, Italy. Eur Respir J 2001; 17: 881-886.

15. Gruppo collaborativo SIDRIA. Frequenza di asma bronchiale in diverse aree italiane. Riv Ital Pediatr 1997; 23: 245-253.

16. Gruppo collaborativo SIDRIA. Asthma and respiratory symptoms in 6-7 yr old Italian children: gender, latitude, urbanization and socioeconomic factors. Eur Resp $J$ 1997; 10: 1780-1786.

17. Gruppo collaborativo SIDRIA. La frequenza dell'asma pediatrico in diverse aree italiane. I risultati di SIDRIA. Epid Prev 1997; 21: 235-242.
18. Gruppo collaborativo SIDRIA. La frequenza dei fattori di rischio per l'asma bronchiale in varie aree italiane. Epid Prev 1997; 21: 243-251.

19. ISAAC Co-ordinating Committee. Manual of the International Study of Asthma and Allergies in Childhood (ISAAC). Bochum and Auckland; ISAAC Co-ordinating Committee, 1992.

20. Stata Corporation. Stata Statistical software: release 8.0. College station (TX, USA) 2003.

21. Pearce N, Weiland S, Keil U, et al. Self reported prevalence of asthma symptoms children in Australia, England, Germany and New Zealand: an international comparison using the ISAAC protocol. Eur Respir J 1993; 6: $1455-1461$

22. Jarvis D, Chinn S, Luczynska C, Burney P. Association of respiratory symptoms and lung function in young adults with use of domestic gas appliances. Lancet 1996; 347: 426-431.

23. Strachan D, Carey I. Home environment and severe asthma in adolescence: a population based case-control study. BMJ 1995; 311: 1053-1056.

24. NHLBI (National Heart Lung and Blood Institute) Global initiative for asthma. Global strategy for asthma management and prevention. NHLBI/WHO workshop report (march 1993). Publication number 95-3659, 1995.

25. Goldman M, Rachmiel M, Gendler L, et al. Decrease in asthma mortality rate in Israel from 1991-1995: is it related to increased use of inhaled corticosteroids? $\mathrm{J} \mathrm{Al}$ lergy Clin Immunol 2000; 105: 71-74.

26. Kumana CR, Kou M, Lauder IJ, et al. Increasing use of inhaled steroids associated with declining asthma mortality. J Asthma 2001; 38: 161-167.

27. Cadum E, Berti G., Demaria M., Grosa M. Effetti a breve termine dell'inquinamento sulla salute: Torino 19911998. Epid Prev 2001: 25 (2) suppl: 56-57.

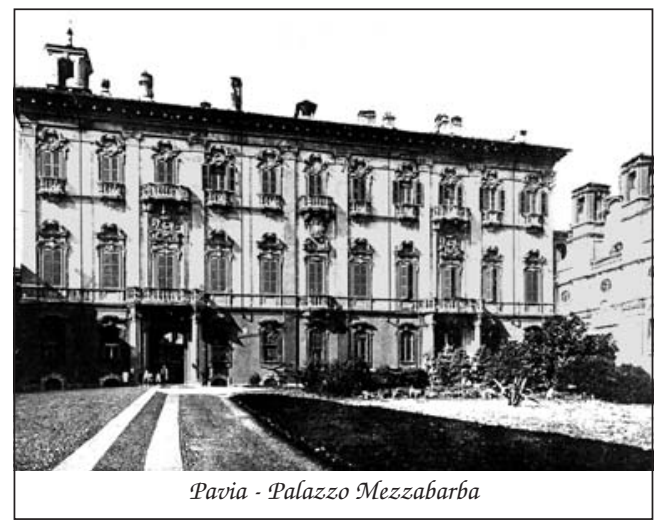

